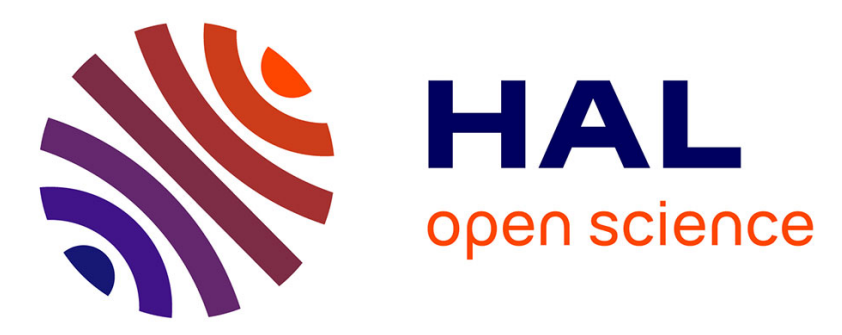

\title{
Microfluidic chips for plasma flow chemistry. Application to controlled oxidative processes
}

Julien Wengler, Stéphanie Ognier, Mengxue Zhang, Etienne Levernier, Cedric Guyon, Cyril Ollivier, Louis Fensterbank, Michael Tatoulian

\section{- To cite this version:}

Julien Wengler, Stéphanie Ognier, Mengxue Zhang, Etienne Levernier, Cedric Guyon, et al.. Microfluidic chips for plasma flow chemistry. Application to controlled oxidative processes. Reaction Chemistry \& Engineering, 2018, 3 (6), pp.930-941. 10.1039/C8RE00122G . hal-01949441

\section{HAL Id: hal-01949441 https: / hal.sorbonne-universite.fr/hal-01949441}

Submitted on 10 Dec 2018

HAL is a multi-disciplinary open access archive for the deposit and dissemination of scientific research documents, whether they are published or not. The documents may come from teaching and research institutions in France or abroad, or from public or private research centers.
L'archive ouverte pluridisciplinaire HAL, est destinée au dépôt et à la diffusion de documents scientifiques de niveau recherche, publiés ou non, émanant des établissements d'enseignement et de recherche français ou étrangers, des laboratoires publics ou privés. 


\title{
Microfluidic chips for plasma flow chemistry. Applica- tion to controlled oxidative processes.
}

\author{
Julien Wengler ${ }^{a b \ddagger}$, Stéphanie Ognier*a ${ }^{*}$ Mengxue Zhang ${ }^{a}$, Etienne Levernier ${ }^{b}$, Cedric \\ Guyon $^{a}$, Cyril Ollivier ${ }^{b}$, Louis Fensterbank ${ }^{* b}$ and Michael Tatoulian*a
}

\begin{abstract}
The present paper relates the integration of nonthermal plasma inside a biphasic gas-liquid microfluidic chip. It evaluates the ability of plasma activation to become a synthetic tool in organic chemistry, operating in mild conditions (room temperature, atmospheric pressure) and without catalyst. Few preceding works on plasma chemistry involved a liquid phase and none of them was able to handle the high reactivity of plasma to achieve both high conversion rate and selective reactions. We fabricated a glass-polymer microfluidic chip comprising a one metre long serpentine channel, in which a parallel gas-liquid flow was stabilized thanks to a specific steplike cross-sectional shape. Transparent ITO electrodes, deposited on both sides of the chip and linked to a AC high voltage source, produced a dielectric barrier discharge all along the channel. We assessed the behaviour of the flow through optical observations and characterized the discharge through electrical measurements and real time intensified-CCD monitoring. We report the successful treatment of liquid cyclohexane with an oxygen plasma inside our chip. The GC analysis of the outflowing liquid revealed only a partial oxidation of cyclohexane into a mixture of cyclohexanol, cyclohexanone (both industrially known as "KA oil") and cyclohexyl hydroperoxide, with a total selectivity above $70 \%$ and conversion up to $30 \%$. This indicates that alkanes can be activated and functionalized by means of plasma discharges, in a controlled way. In that respect, we claim to have successfully overcome some of the barriers to an industrially relevant plasma chemistry. We believe that the combined use of plasma and microfluidic technologies is essential to the development of this new field of research.
\end{abstract}

\section{Introduction}

In the search for cleaner, more efficient and cost-reduced reactions for synthetic chemistry, non-thermal atmospheric pressure plasma discharges, and more specifically dielectric barrier discharges $\frac{122}{}$ (DBD) have a high potential of novelty. They indeed allow reactive species, such as radicals, neutrals in different excited states, to be generated at room temperature and atmospheric pressure.

Presently, the well-established applications of atmospheric pressure plasmas are mainly surface treatment ${ }^{3+16}$ (hydrophilic/phobic, antifouling, antifog, corrosion resistant...), ozone gener-

\footnotetext{
* Corresponding author

a Chimie ParisTech, PSL Université Paris, CNRS, Institut de Recherche de Chimie Paris, 2PM Group, 11 rue Pierre et Marie Curie 75005 Paris, France

${ }^{b}$ Sorbonne Université, CNRS, Institut Parisien de Chimie Moléculaire, MACO group, UMR 8232, 4 place Jussieu 75005 Paris

$\ddagger$ This work was performed at Institut Pierre-Gilles de Gennes, PSL Research University, 6 rue Jean Calvin, 75005 Paris, France, Tel: +331 40795973.
}

ation $^{7-12}$, air and water depollution (including volative organic compounds removal) 113,16 or plasma-assisted combustion 17 . Meanwhile, plasmachemical synthesis has barely ventured beyond (nano-)material synthesis ${ }^{18}[24$, plasma-assisted polymerization $25 \mid 27$ and a couple of gas-phase reactions (including benzene hydroxylation $^{28-32}$ and methane reforming $33-37$ ).

A significant part of present and past plasma-enhanced chemical reactions involve a catalyst, either activated or regenerated by the plasma $34 \mid 38,42$. These plasma catalysis have exhibited a relatively low cost in equipment as well as a high energy efficiency, though still facing difficulties to replace conventional processes at a large scale $\underline{42}$.

In order to develop 'greener' chemical processes, researchers have also studied catalyst free plasma-chemical synthesis 2930143 49. It is possible to generate energetic reactive species at room temperature within a plasma discharge, which could lead to new chemical routes and easy-to-trigger reactivities without the use of catalysts. Moreover, the reaction mechanisms for 
catalyst-plasma coupling are often not well known yet, which hinders its development compared to catalyst-free plasma processes.

Due to the extreme reactivity of plasma-induced species, avoiding the fast quenching of reactive species at atmospheric pressure and maintaining a controlled reactivity without overreaction remain delicate issues to be addressed 28. It has so far been impossible to achieve both high conversion and high selectivity with conventional plasma reactors 29150 . Reducing the size of the reactor and adapting its precise shape would be a part of the answer.

The past 20 years have seen much attractiveness gained by microplasma ${ }^{51+53}$ - i.e. plasma in submillimetre gaps. At the same time, the field of microfluidics was born, and many saw in microreactors a promising tool for flow chemistry and process intensification $\sqrt{54 \sqrt[56]{5}}$ thanks to the speciticities of small-scale physics, namely enhanced mass and energy transfers with a large surface over volume ratio, which enables the precise controls of flow, the handling of toxic or explosive chemicals, the precise patterning of reaction conditions 57 . Today, standard or customized microfluidic reactors are commonly proposed by many supplyers.

Microplasmas for chemistry have been triggered in capillaries $40|48| 58 \mid 59$, in arrays of channels microengineered in various materials $\sqrt{1260+64}$, in specially resistant substrates ${ }^{65}$, in wide simple millifluidic channels ${ }^{29|66| 67}$ (even inside a bubble ${ }^{68 / 69}$ ), in a channel as a surface discharge ${ }^{70}$ or triggered by outer electrodes at its ends ${ }^{7172}$, in a modified commercial microfluidic channel ${ }^{11}$ and in a SU8 channels and ITO electrodes ${ }^{73}$ (but without reaction). The reactions performed in microchannels have merely been ozone generation and the hydroxylation of benzene and toluene ${ }^{12229}$, in gas phase only.

We report here a method to implement DBD plasma inside a microfluidic chip which are elaborated with standard microfabrication techniques, and which are able to handle gas and liquid through a customizable channel shape,. Such microchips are specifically dedicated to synthetic plasma chemistry at room temperature and atmospheric pressure, and to use a liquid phase as reactant, while many historical attempts to perform chemical synthesis by the means of plasma discharges have been limited to gas only ${ }^{74-76}$, which greatly limits the total mass of reactant involved in the transformations. Apart from water treatment purposes, liquid phases have only been used as a mere reservoir of reactive species, which were to be involved in a gas-phase reaction. 50 [77

Working at the micro scale provides us with a high surface-tovolume ratio which optimizes mass transfer between the plasma and the liquid, as advised by Malik 78 . Some preceding reactors comprised either liquid sprays or a liquid film flowing over a surface 79 , but they clearly lacked uniformity in the liquid flow. Another strategy is the use of biphasic reactors with gas bubbles injected in a flowing liquid. Matsui et al. 80 used such a two-phase flow reactor to decompose acetic acid in water, and showed good results for this purpose, that is a complete oxidation. The drawbacks of this reactor are however the large size of the bubbles (between 0,1 and $1 \mathrm{~cm}$ ), a little control of their shape, and the impossibility to manage a partial oxidation without overreaction.

We had already developed a plasma microreactor where microsized bubbles have been generated using a traditional flowfocusing geometry 81 . P3. Plasma discharges were generated re- peatedly in the micro-sized dispersed gas bubbles moving in the continuous liquid phase. In the case of a water/argon biphasic flow, the production of gaseous $\mathrm{OH}^{-}$radicals and their transfer in water has been evidenced and quantified, making hydroxylation reactions possible. However, in these slug flow reactors, the volumes of liquid and gas are in the same order of magnitude, while their densities are in a roughly thousand-fold ratio. This induces the thousand-fold ratio of quantity of matter between the plasma and the liquid, which implies the impossibility to quantitatively convert a liquid with a gaseous reactant.

The innovation of the present work lies in the possibility to make a parallel biphasic microflow with gas and liquid in a microfluidic device, and to create a homogeneous plasma state inside the gas. This novel flow configuration is capable of intensifying the mass transfer to the liquid. This was possible thanks to: (i) the utilization of the capillary forces to efficiently stabilize the biphasic flow by means of a triple line pinning at a sharp edge parallel to the flow direction as demonstrated by Oliver et al. $\frac{.84}{\mathrm{~L}}, \mathrm{Li}-$ imatainen et al. $\frac{85}{6}$, Hu et al. $\frac{86}{}$; (ii) the integration of electrodes in the vicinity of the channel, which can support more than $10 \mathrm{kV}$ potential difference. $\frac{87}{}$

To prove the feasibility and the relevance of plasma chemistry, we illustrate its use for the challenging oxidation of alkyl $\mathrm{C}-\mathrm{H}$ bonds in the case of cyclohexane. 88 This reaction is of high industrial interest and is the first step towards synthesis of polyamid fibers (such as Nylon-6 and Nylon-6,6). $\frac{89}{}$ It yields a mixture of cyclohexanol and cyclohexanone ("KA oil") and currently requires harsh conditions ( 8 bar to $15 \mathrm{bar}$ and $125^{\circ} \mathrm{C}$ to $165^{\circ} \mathrm{C}$ ), as well as the presence of cobalt catalyst. ${ }^{88189}$ Also, the conversion is kept low $(<10 \%)$ to avoid side-reactions - according to a numerical kinetic modelling, Bhattacharya and Mungikar ${ }^{90}$ showed a decrease of selectivity above a $2 \%$ conversion - , and the maximum concentration of oxygen is limited to a few percents because of the risks of explosion. ${ }^{.91}$ To the best of our knowledge, no safer and more efficient process has been proposed so far.

\section{Experimental}

\section{Chip fabrication}

Our microfluidic chip was fabricated following the microfluidic sticker method ${ }^{92}$, using Norland Optical Adhesive 81 (NOA-81) polymer and glass slides and coverslips. Standard soft lithography techniques were used to make SU8 molds and PDMS stamps. A similar procedure has already been presented in previous works. $\frac{8182}{82}$

Gold-doped ITO (Indium-Tin Oxide) electrodes were deposited on $150 \mu \mathrm{m}$-thick D263M glass coverslips (Menzel-Gläser, $24 \mathrm{~mm} \times 60 \mathrm{~mm}$ ) by the sputtering technique to serve as electrodes, as decribed in 81 . Aluminium foil and silver paints connected these electrodes to the external electric circuit.

One of such coverslips was glued with NOA-81 to a $1 \mathrm{~mm}$ thick standard glass slide for hardness purpose, the electrode facing the glass slide. Bores were then sand-drilled throughout these layers. This constituted the first part of the chip, including one electrode (Fig,2, \#1).

In parallel, the channel design (sketched on Fig 1) was trans- 
ferred to a 2-layer SU8 mould on silicon by soft lithography techniques. A positive replica of the targeted channel was thus produced. Actual depths were assessed with a Wyko NT 9100 Optical Profilometer for each execution.

Mixture of liquid PolyDiMethylSiloxane (PDMS) and crosslinking agent (RTV 615, Momentive GmbH, Germany, ratio 9:1) was then poured and thermally cross-linked over this positive SU8 mould to become a negative replica of the channel. Once properly degased, the PDMS stamp was utilized following the microfluidic sticker method first described by Bartolo et al. ${ }^{.92}$, and previously used in our team. ${ }^{82}$ A layer of NOA-81 was structured according to out channel pattern, and adequately UV-cured to bond a second electrode-bearing coverslip to the aforementioned first part of the chip.

The channel height embodied a compromise between a thinner value which caused high pressure drops, and a higher value which would be complicated and time-consuming to achieve using SU8. The width ratio of the liquid and gas parts was also considered a balance between the quantity of excited species produces in the gas volume and the losses by stripping.

The length of the channel under the electrodes was $1 \mathrm{~m}$, which gives a $35 \mu \mathrm{l}$ total volumes, distributed between $10 \mu \mathrm{l}$ for the liquid low part and $25 \mu \mathrm{l}$ for the gas flow part.

Special care was eventually taken to ensure that no sparking would occur at the electrical connection with the ITO, and to properly isolate the electrodes from the outside. Fluidic connections were made with Nanoport coned assemblies (IDEX Health \& Science) and 1/16" PTFE tubings.

The chip eventually connected to several systems controlling both the fluidic flows and the electric excitation used to create the plasma (Fig 3).

\section{Fluidic part}

The gas flows were managed by means of mass flow controllers (Bronkhorst FG-201CV). The liquid flows were produced by a syringe driver (kdScientific Legato 180). In both cases, the specific assigned rate directly determined their dwelling time in the chip.

Inert gases (Ar, He...) as well as reactive gases $\left(\mathrm{O}_{2}, \mathrm{H}_{2}, \mathrm{H}_{2} \mathrm{O}\right.$, $\mathrm{NH}_{3}, \mathrm{CO}_{2}, \mathrm{CO}, \mathrm{N}_{2} \ldots$ ) have been used in our experiments.

The stripping of volatile substrates like cyclohexane was a major concern since the loss of reactant affects the assessment of the final conversion. To reduce the stripping, the out-flowing liquid+gas mixture was led through PTFE tubing into a vial immersed in cold water, before exiting via a second tubing. The vapours were partially condensed, thus reducing the net stripping. For example, cyclohexane losses dropped from around $30 \%$ in direct exit, to only $14 \% \pm 5 \%$ with the cold bath (liquid flow rate $6 \mu \mathrm{l} \cdot \mathrm{min}^{-1}$ and argon flow rate $1 \mathrm{ml} \cdot \mathrm{min}^{-1}$ ). In that case, a bath temperature of $8{ }^{\circ} \mathrm{C}$ prevents the freezing of cyclohexane $\left(T_{m}=6.47^{\circ} \mathrm{C}\right.$ ) which would cause the clogging of the tubing.

\section{Electrical connections and plasma generation}

Dielectric Barrier Discharge. From the plasma discharge point of view, our device geometry corresponds to what is called Dielectric Barrier Discharge (DBD), for which one or two dielectric lay-
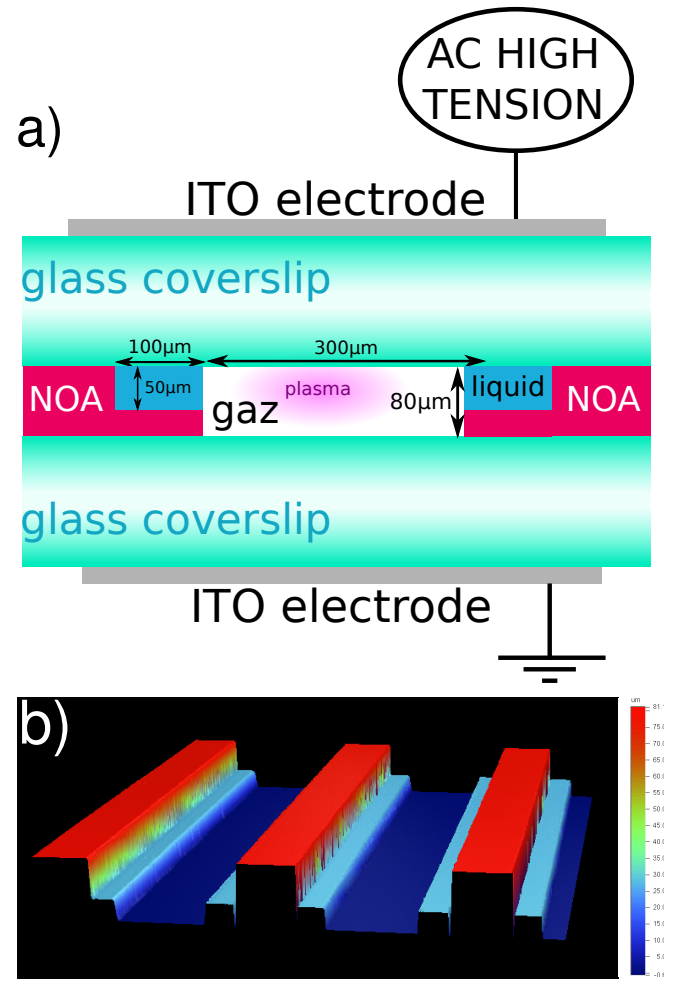

C)
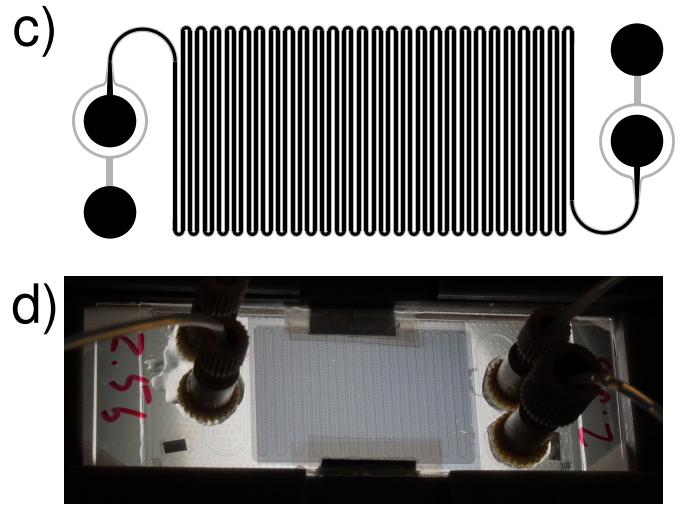

e)

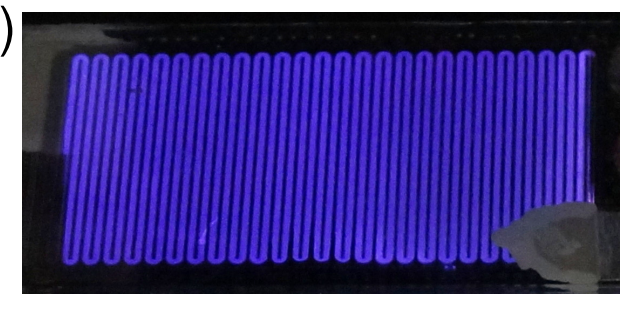

Fig. 1 a) Cross-section of the channel. The NOA walls define two types of sub-channels: one dedicated to gas flow, on the middle, deep; another dedicated to liquid flow, on the sides, shallow. Thin layers of $60 \mathrm{~nm}$ golddoped ITO were deposited on the outer side of both coverslips and linked to a high tension source. b) 3D view of the channel reconstructed by optical profilometry. c) Top-view of the channel. The deep and shallow parts are depicted in black and grey, respectively. Its total length is about 1 metre. The big circles stand for the inlets and outlets for liquid and gas phases. d) Picture of our chip, back-illuminated under the CCD-camera, and whose inlets and outlets were connected to PTFE tubing through Nanoport connectors. Looking carefully, one may sight the biphasic flow inside the channel. The gray rectangle in the middle of the chip is the two ITO/Au electrode, above and below the channel, which overlap. e) Argon plasma without liquid. 


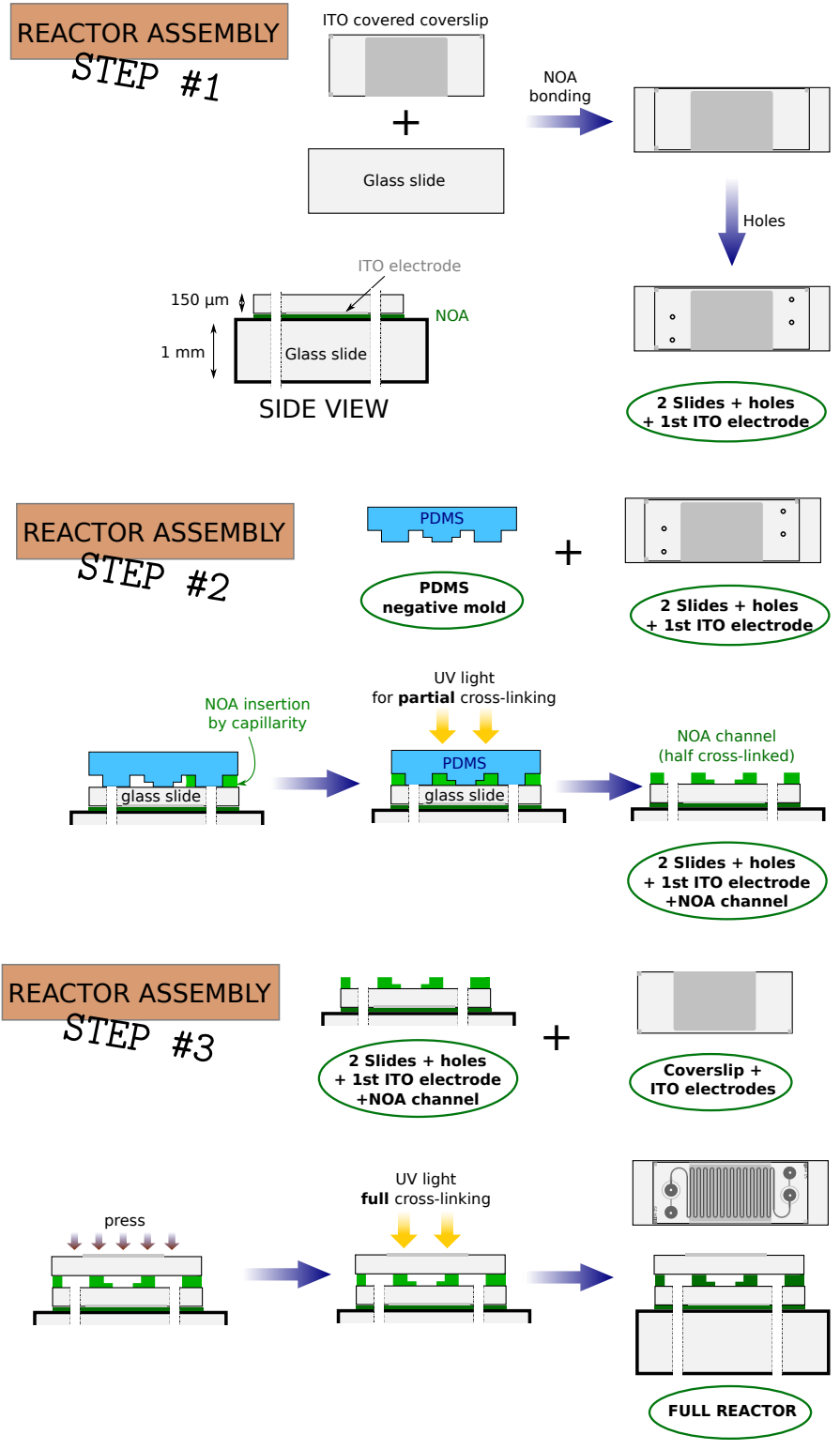

Fig. 2 The sequence of assembly steps of our plasma microchip. ers are inserted between the electrodes, thus preventing the formation of hot electric arcs, detrimental to the device integrity 2 . Here, a double-DBD configuration, with two dielectric layers (the glass coverslips) on both sides of plasma zone, was chosen so that no electrode would be in direct contact with the plasma. Otherwise, one would certainly expect some electrochemical reactions. Also the slow vaporization of the electrode represents a high risk of reducing its lifetime and allowing nanoparticules to get into the plasma and potentially modify its reactivity 93 .

Electrical connections. The electric high voltage excitation was generated by amplifying (TREK 10/40A High Voltage Amplifier $\mathrm{x} 1000$ ) the output of a function generator (RSpro Arbitrary Function Generator AFG-21025). The frequency used were of the order of $100 \mathrm{~Hz}$ to $2000 \mathrm{~Hz}$, with a amplitude up to $10 \mathrm{kV}$ pp. All electric signals were monitored with an oscilloscope (Teledyne LeCroy WaveSurfer 10, $1 \mathrm{GHz}$ ) through (high) voltage probes (Teledyne LeCroy PP024 500 MHz 10:1 ; TesTec HVP 15HF HighVoltage Passive Probe $50 \mathrm{MHz}, 30 \mathrm{kV}$ 1000:1). The intensity through the reactor was recorded by a Rogowski coil (Pearson current monitor model 2877, $200 \mathrm{MHz}$ ) at the low voltage end of the circuit.

Power assessment. In the objective of being reproducible and of calculating the energetic efficiency of our method, the power transferred must be assessed. It was so by the Lissajous method 94 96: a 3.2nF capacitor was placed in series with the reactor, and the voltage drops $V_{r}$, across the reactor, and $V_{c}$, across the capacity, were measured with suited voltage probes and displayed as a XY plot. The capacitor gave access to the accumulated charge transferred through the reactor (capacitive current + discharge current). In the absence of any discharge, both voltages are in phase and the plot reduces to a straight line. But as discharges occur, small amounts of charges come across the plasma in the channel and are deposited on the capacitance (discharge current). This deviation from the pure capacitive behaviour of the reactor proves the presence of discharges and translates into a parallelogram-shaped XY figure. In addition, the voltage drop $V_{c}$ across the capacitance is proportional to its charge $Q$. Therefore, the area of the parallelogram figure accounts for the energy transferred to the reactor during one period (Fig 4):

$$
E=\oint V_{r} d Q
$$

Hence, with the frequency $f$ we get the average power $\mathscr{P}$ transferred to the reactor:

$$
\mathscr{P}=f \oint V_{r} d Q
$$

In practice, we randomly encountered phase shifts of both signals, whose origins remain unelucidated, and which lead to a "rugby ball" shape of the Lissajous figure. We think it might come from a transient resistive behaviour of the electrodes, possibly linked with local heating or connection defects. We circumvented it by artificially compensating the phase shift in the oscilloscope, until we reached the best looking parallelogram shape. 


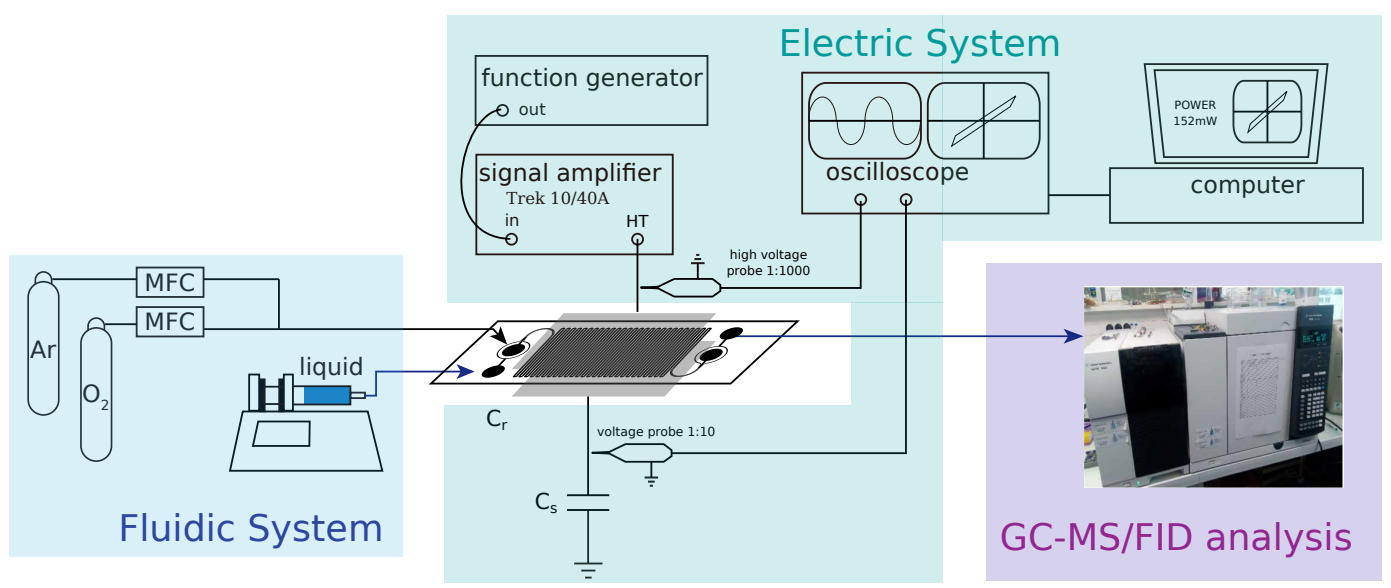

Fig. 3 Illustration of the different connections to our chip.

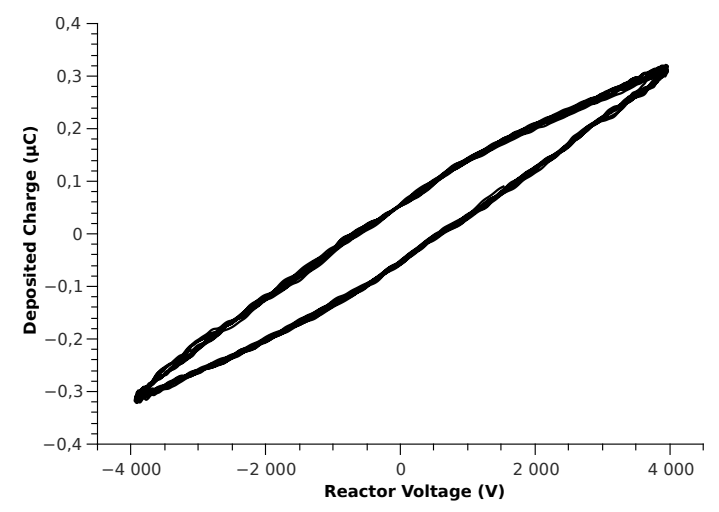

Fig. 4 Lissajous curve displaying the deposited charge $Q$ against the voltage $V_{r}$ across the reactor during a plasma discharges. The area of the parallelogram shaped readily gives the energy transferred per period.

\section{Optical characterisation}

The chip was disposed under a macroscope (Leica Z16 APO, Germany), onto which was mounted either (1) a CCD camera (PixeLINK PL-B781U) for flow visualisation, the chip being backilluminated by a diffuse LED lamp, or (2) an intensified-CCD camera (PiMAX4, Princeton Instruments, USA) for plasma visualisation.

\section{Chemical reactions and analysis}

A gas-chromatograph with FID and MS detectors (Agilent 7890B GC system + 8977B MSD) was used for identification and quantification of the chemical species present in the liquid phase.

\section{Results \& discussion}

\section{Flow control}

For our application in plasma chemistry, the flows needed to be as stable and controlled as possible. The plasma discharge occurred only in the gas phase, and the transfer of active species was totally dependent on the gas/liquid interface. The interface geometry should be constant over time, as well as the flow rates of both phases, and specifically the liquid phase that we want to convert.

Alhough many techniques exist to manage immiscible liquid- liquid flows, gas-liquid flows are hard to control and to model. 97 The fundamental reasons surely are the huge difference of density and viscosity between gas and liquid, and the very fast evaporation and diffusion effects in gases.

To maintain the gas-liquid interface in a constant position, the solution was to pin the triple line. This phenomenon can be daily seen in water drops on a dirty glass surface: their front and rear triple lines tend to stick between areas with different hydrophobicity. An easy way to achieve triple line pinning would have been to pattern the surface chemistry to create hydrophobic areas, but such a strategy was unusable because the plasma would quickly alter the surface chemistry with etching reactions.

The alternative we chose was to create a triple-line pinning point by means of a physical discontinuity. Indeed, discontinuous sharp features, or in other words highly curved surfaces, have been known for long to prevent liquid from spreading $84 \mid 98$. This property can even lead to the fabrication of superhydrophobic surfaces, in the extreme case of undercut features. $\frac{85}{}$

This interfacial phenomenon stems from the ability of the macroscopic gas-liquid interface curvature to vary while keeping the microscopic contact angle constant, by slightly shifting the position of the triple line. The order of magnitude of this shift is the radius of curvature of the sharp feature (Fig $[5$ ), which can easily be set much smaller than the macroscopic dimensions of the interface.

The filling of channels can be modified by the presence of sharp edges 99 , and holes perpendicular to the channel can stabilise gasliquid flow. $\frac{86}{}$ Aota et al. 100 managed to guide a narrow liquid flow in a specific part of a wider and deeper channel thanks to a difference of height, even though only for a limited channel length.

We extended this idea by designing a side step along the full length of our channel (Fig 1 a). The performance of the liquid-gas separation was assessed with the CCD camera. Fig 61 illustrates in false colours a flow of cyclohexane and argon in two segments of channel: one with, and the other without the step (homogeneous $80 \mu \mathrm{m}$ height). The liquid flow rate was kept constant at $12 \mu \mathrm{l} . \mathrm{min}^{-1}$ while the gaseous one was varied from $0.5 \mathrm{ml} . \mathrm{min}^{-1}$ to $6 \mathrm{ml} \cdot \mathrm{min}^{-1}$. Without any step, the flow was already quite sta- 


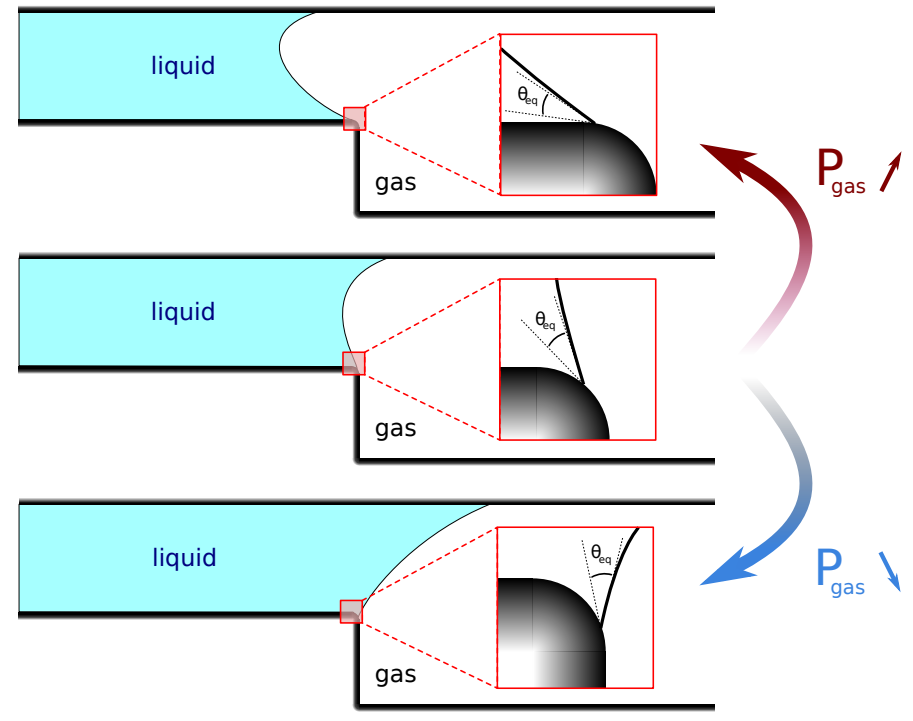

Fig. 5 Illustration of the principle of triple line pinning at a sharp edge. From the middle case, the pressure in the gas is either increased or reduced. This yields an overall movement of the interface to the left or the right, especially in the top part of the channel. The lower contact line however does not macroscopically move: it is pinned. The equilibrium contact angle $\theta_{e q}$ can be kept while the triple line slightly shifts. This is allowed by the small radius of curvature of the surface, whose orientation quickly varies when shifting along it.

ble with a gas flow surrounded by a liquid flow, but the liquid film underwent a thinning with increasing gaseous flow rate, i.e. with increasing gas pressure. For a given liquid flow rate, this clearly influenced the velocity and then the residence time of the liquid inside the reactor, which is a key parameter to control the reactivity. With the step shape however, the thickness of the liquid flow remained fairly constant in the linear parts. Changes occurred in the U-turns, but remained negligible since they only represented about $10 \%$ of the total channel length. What is more, the step prevented the emergence of a plug flow when the gas/liquid flow rate ratio become too low, as can be seen on Fig 6 .

This special step shape also offered the opportunity to work with aqueous solutions, even though the separation was less efficient. The behaviour of water illustrated on Fig 6p) evidenced the need of the step to achieve a stable flow. In practice, the stability was much lower with an aqueous medium, owing to the high surface tension of water with respect to organic phases and to their different affinity for glass and NOA-81. Indeed, two out of three sides of the channel part dedicated to liquid flow were made out of NOA-81. Wettability of glass and NOA-81 for these liquids was evaluated with a Drop Shape Analyser (Krüss). The measured contact angle of $65^{\circ} \pm 3^{\circ}$ for water on NOA-81 made it hydrophobic, and water then tended to leave the shallow part to be in contact with a wider glass surface, that water fully wetted. On the contrary, similar contact angles were measured for cyclohexane on NOA-81 $\left(10^{\circ} \pm 2^{\circ}\right)$ and on a glass coverslip $\left(6^{\circ} \pm 1^{\circ}\right)$. The line pinning was fully effective with that liquid.

To sum it up, we identified two main advantages for the step. (i) In the cyclohexane flow (Fig 6) it prevented the thinning of the liquid flow with increasing gas flow rate, and ensured a constant
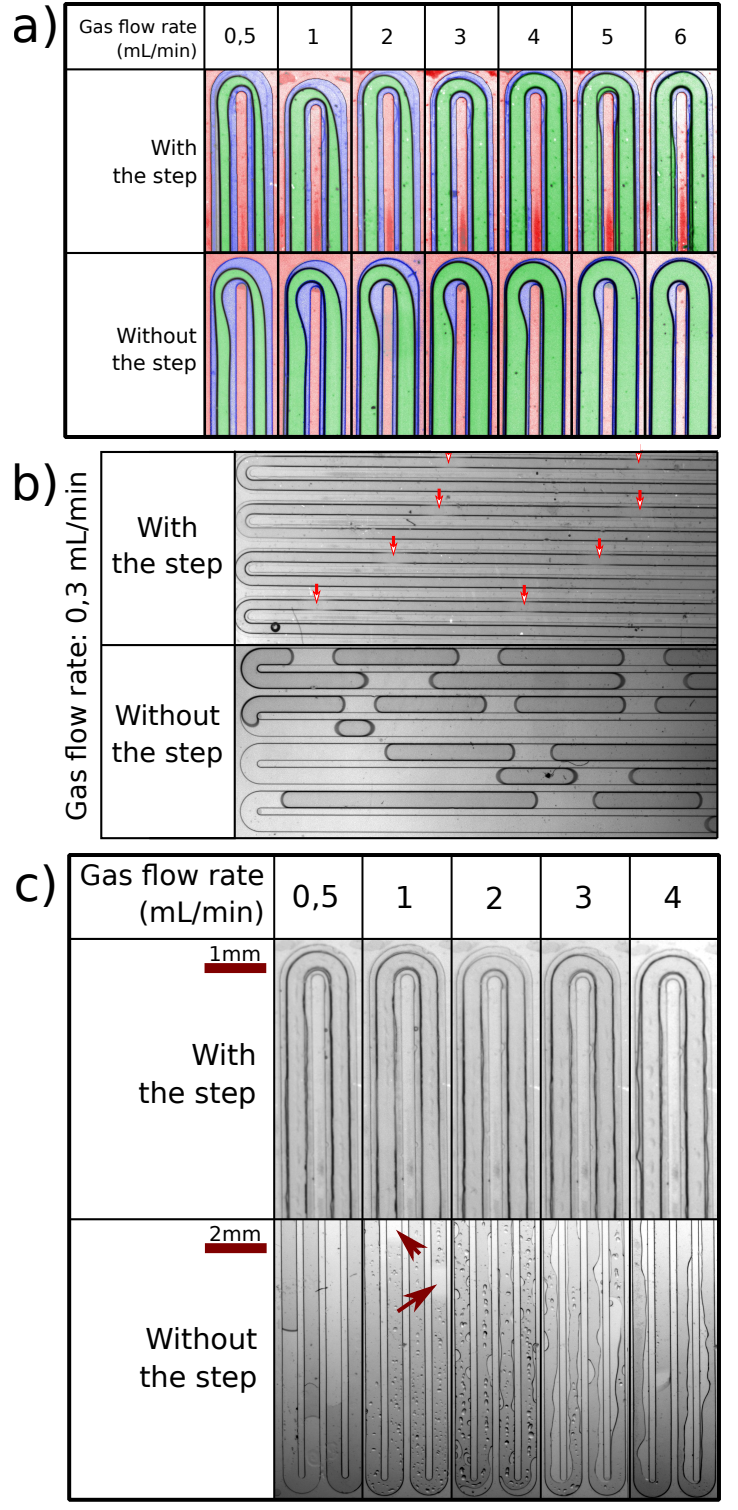

Fig. 6 CCD pictures of biphasic flows with cyclohexane or water in the vicinity of a U-turn, with (cf. Fig 1$]$ or without (uniform $80 \mu \mathrm{m}$ height) the step shape. a) is in false colours while for b) and c) the liquid appears brighter and the gas darker. a) Biphasic flow of cyclohexane (blue) and gas (green) for various gas flow rates (walls in red) and a $12 \mu \mathrm{l} . \mathrm{min}^{-1}$ liquid flow rate. The step limits the thinning of the liquid flow with increasing gas flow rate. b) Same configuration for very low $0.3 \mathrm{ml} . \mathrm{min}^{-1}$ gas flow rate and $12 \mu \mathrm{l} . \mathrm{min}^{-1}$ liquid flow rate: the stable flow turned into a plug flow, unless the step the step prevented it. Stabilisation with the step is however not perfect: both liquid sides met regularly along the channel to form thin bridges which appeared blurred due to the acquisition time of the camera (see arrows). c) Same reactors with a water flow. Without the step, we observed either a plug flow (low gas flow rates, see arrows in the $1 \mathrm{ml} \cdot \mathrm{min}^{-1}$ case) of an erratic movement of small amounts of liquid (higher gas flow rates). In both cases, drops of water were laying on the top or bottom glass side of the channel, resulting from either a transient flow which previously reached this part, or from the evaporation and condensation of water on this hydrophilic surface. 
flow cross-section and residence time of the liquid, which were crucial parameters. (ii) In the water flow, it basically allowed the generation of stable biphasic flows. Although the flow with the step was far from smooth, gas could still flow through the liquid, which was evenly spread along the channel. Otherwise, only plug flows or scattered water droplets were observed.

\section{Plasma discharge}

The plasma discharge was optically diagnosed thanks to an intensified charge-coupled device (iCCD) camera (Pimax4, Princeton Instruments) through a macroscope (Leica Z16 APO). A dark environment was necessary for the detection of weak optical emission of electrical discharges, due to the small volume concerned.

Fig.7 7 shows the light emitted by the plasma homogeneously along the channel as the discharge was triggered with liquid cyclohexane and argon gas flowing side by side. A zoom (Fig 7p) shows a homogeneous discharge located in the central, deeper, part of the channel, which was confirmed by the same image taken with only gas flowing through the channel (Fig 7f) on which the deeper and shallower parts gave a stronger and weaker signal, respectively. This furthermore indicated that the discharge was vertically homogeneous, given that the ratio of brightness on the picture, 1.89 , and the ratio of the corresponding channel heights 1.64 were very close. The discrepancy between these values could be due to a difference in reflection on glass and NOA-81 surfaces.

A capacity of $78 \mathrm{pF}$ was found for the reactor, utilizing a capacitive tension divider bridge with a $2 \mathrm{nF}$ capacitor through a $1 \mathrm{kHz}$ sine excitation.

Our plasma discharge, triggered by a AC high voltage, exhibited the classical pattern of a succession of random microdischarges. Such microdischarges occur when the electric field intensity as seen by the gas - i.e. the applied voltage added to field created by the charges deposited on the dielectrics during the preceding microdischarges - exceeds the breakdown voltage of the gas.

The current peaks corresponding to each microdischarge superimposed with the sine shaped capacitive current, with a $\pi / 2$ phase with respect to the voltage (see Fig 7d). A microdischarge was typically $100 \mathrm{~ns}$ long and released an energy of a few $\mu \mathrm{J}$. With a sine voltage around the $\mathrm{kHz}$ range, this value is coherent with the power of a few hundreds $\mathrm{mW}$ obtained with the Lissajous method.

Only a slight increase in temperature of a few tens of degrees was measured when working with higher voltages. This is believed to be almost entirely due to the Joule heating of the capacitive current in the $R_{\square} \simeq 100 \Omega$ ITO electrodes, since the heating drops when one electrode is replaced with gold. Besides, a numerical simulation of thermal transfers also indicates less than $1{ }^{\circ} \mathrm{C}$ heating of the reactor when only accounting for the plasma discharge.

\section{Partial oxidation of cyclohexane}

We studied the response of simple aliphatic hydrocarbons like cyclohexane to reactive oxygen species (ROS). After a recent set of

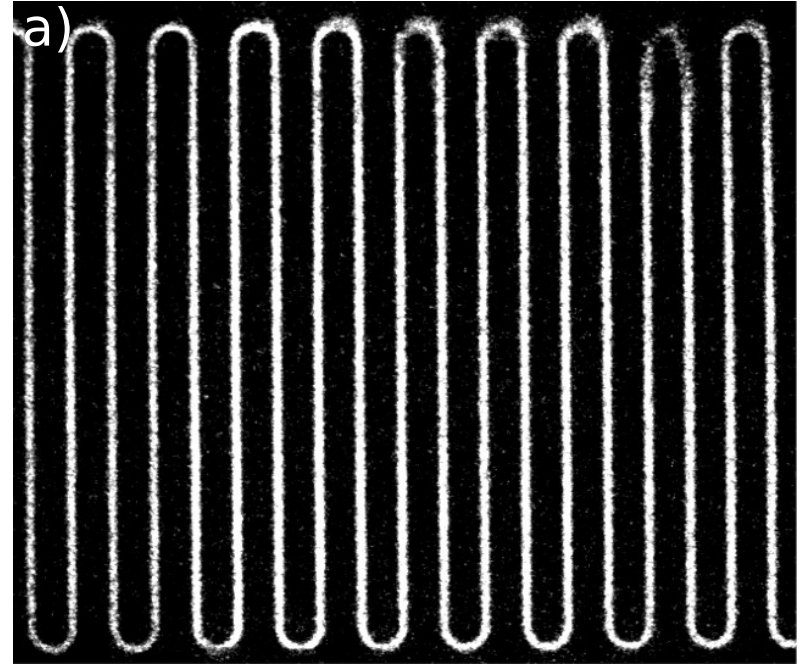

b)
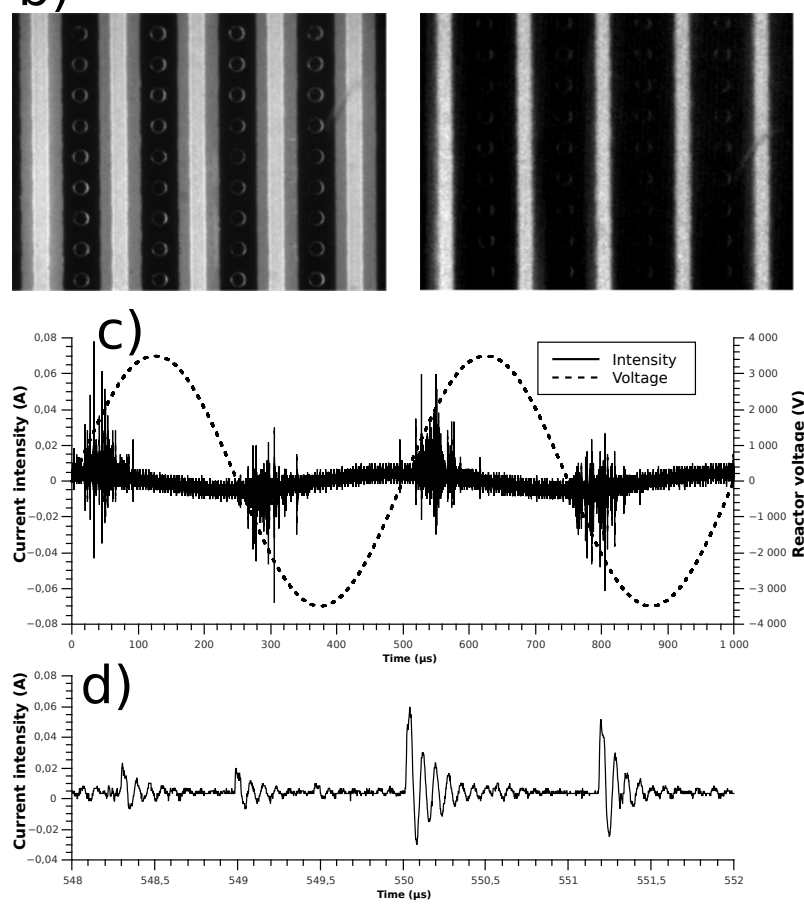

Fig. 7 Emission of light from a plasma discharge in argon as seen with the iCCD camera in an older version of the chip (the circular features are for microfabrication purpose only and are not relevant here), whose deeper part of the channel was $123 \mu \mathrm{m}$ high and the shallower part $75 \mu \mathrm{m}$ high. a) View of the whole chip. b) Zoom on the channel when argon gas and liquid cyclohexane were flowing side by side. c) Zoom on the channel when only argon gas was flowing. d) Intensity measured for a AC $2 \mathrm{kHz}$ excitation with $\mathrm{O}_{2}$ gas and cyclohexane flow. e) Zoom on a few current peaks corresponding to several random microdischarges, whose duration is about $100 \mathrm{~ns}$ (the oscillations are an artefact created by the measurement circuit). 
promising experiments carried out with a gas-liquid plasma reactor $50777101-103$, we were expecting the following products to be formed after exposing cyclohexane to plasma-generated oxidising species : cyclohexene, cyclohexanone, cyclohexanol, hexanal, 2-cyclohexenone. In this reactor, the hydrocarbon vapour was introduced in gas phase with argon carrier gas, and the plasma was triggered in the vicinity of a water flow, the latter being the source of oxidative species.

We chose to work on a liquid hydrocarbon as a reactant, because we already had in mind a potential industrial application, where the conversion of a liquid, dense phase is more desirable than the one of a gaseous phase.

Liquid cyclohexane (VWR HiPerSolv CHROMANORM for HPLC, purity min. 99.5\%) was introduced at three different flow rates $\left(6 \mu 1 \cdot \mathrm{min}^{-1}, 12 \mu \mathrm{l} \cdot \mathrm{min}^{-1}\right.$ and $\left.24 \mu \mathrm{l} \cdot \mathrm{min}^{-1}\right)$ in the microreactor together with pure $\mathrm{O}_{2}$ gas at respectively $0.5 \mathrm{ml} \cdot \mathrm{min}^{-1}$, $1.5 \mathrm{ml} \cdot \mathrm{min}^{-1}$ and $2 \mathrm{ml} \cdot \mathrm{min}^{-1}$. These liquid flow rates corresponded respectively to $26 \mathrm{~s}, 52 \mathrm{~s}$ and $108 \mathrm{~s}$ residence time in the plasma zone. The durations were evaluated by allowing the liquid to get inside the reactor with the appropriate flow rate, the gas being already flowing, and by measuring the time taken by the head front of the liquid to travel along the channel length subject to the plasma discharge. We assessed that this measurement reflected the actual mean residence time of liquid during the reaction with a $10 \%$ precision. More precise measurements were not needed for our purpose.

A $2 \mathrm{kHz}$ high voltage sine wave triggered atmospheric pressure dielectric barrier discharges inside the micro-reactor. The amplitude of this signal was set to get a constant power of $500 \mathrm{~mW}$, as measured thanks to the aforementioned electrical setup, and was situated between 6 and $7 \mathrm{kV}$ peak-to-peak.

The ouflowing gas-liquide mixture was collected in a $8^{\circ} \mathrm{C}$ cold trap, which had shown to exhibit only $15 \%$ mass loss when in similar conditions with cyclohexane and without plasma. GCMS/FID analysis of the organic liquid showed three major products of similar quantities and one secondary product. Two of the three major products were positively identified as cyclohexanol and cyclohexanone thanks to MS spectra and by comparison with reference products. The secondary product was likewise identified as cyclohexene. The third major product was positively identified as cyclohexyl hydroperoxide (see Supplementary Informations).

The minority products gathered in the "others" category of Fig 9 are traces of various compounds derived from cyclohexane fragmentation - products lighter than cyclohexane -, subsequent addition of the latter to cyclohexane - products heavier than cyclohexane -, bicyclohexane, cyclohexyl, hydropexoxide, etc.

A residue was also observed in the channel, which could be either a solid or a liquid immiscible with cyclohexane. It could be dissolved in organic solvents such as THF or DCM but they can also attack the NOA surface and delaminate the coverslip. For this reason, analysis results cannot be used because of multiple peaks due to the NOA dissolution. However, looking at the images of the channel covered by the residue (Fig 8 ), we assumed that the volume residue was very small compared to the total volume of the cyclohexane having flowed inside the reactor. We therefore

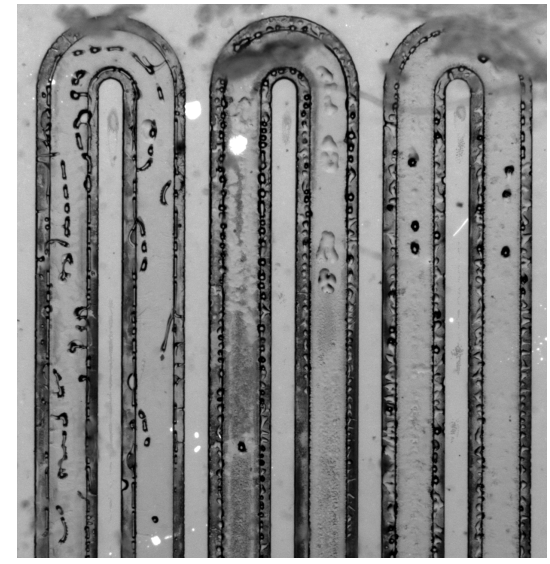

Fig. 8 Photograph of the channel with the residue deposited after the reaction of cyclohexane in an oxygen plasma.

considered it a negligible by-product.

The molar fractions of the different products were assessed with FID quantitative analysis. Response factors of cyclohexanol and cyclohexanone were measured by comparing the areas of the FID peaks for equimolar solutions of cyclohexane and cyclohexanol or cyclohexanone, respectively. Since the response factor of

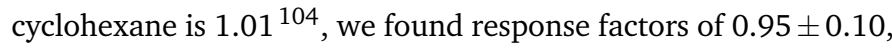
$0.85 \pm 0.10$ and $0.9 \pm 0.1$ for cyclohexene, cyclohexanol and cyclohexanone, respectively. Despite the discrepancy of our result for cyclohexanone with the partial data from Dietz ${ }^{104}$ ( 0.99 for hexene, 0.74 for hexanol, 0.72 for cyclohexanone), we chose to keep our values to work on a full data set measured in the same experimental conditions. In the lack of commercial product, the response factor of cyclohexyl hydroperoxide was taken equal to 1. The molar concentration of each product then equals to the area of the corresponding peak divided by the product of its number of carbon and the response factor. Using this method, we obtained the molar fraction of the different products in the outflowing liquid and we could assess the conversion and selectivity for each of them (Fig 9).

We achieved about $80 \%$ selectivity in oxygenated products, whose multiplicity is not that problematic for potential applications. Not only could they easily be turned into only one product cyclohexanol - by reduction, but they are even usable as such for industrial purposes. The mixture cyclohexanol/cyclohexanone is indeed known as "KA oil" and used as precursor of nylon. Therefore, we decided to count these products together when calculating the selectivity of the reaction. Results are summarized in Fig 9 Increasing the reaction time proportionally improved the overall conversion, which suggests a linear reaction rate. The selectivity reduction is only significant in the $2 \mathrm{~min}$ case, which may be due to the increase of the cyclohexane/oxygen ratio in the gas channel owing to a higher temperature at $104 \mathrm{~s}$ residence time compared to $26 \mathrm{~s}$. The temperature in the microreactor could not been measured but with constant power $(500 \mathrm{~mW})$, the temperature should logically increase when the gas and liquid flow rates decrease.

These results show a significant improvement with respect to previous attempts of controlled oxidation of cyclohexane by 
a)

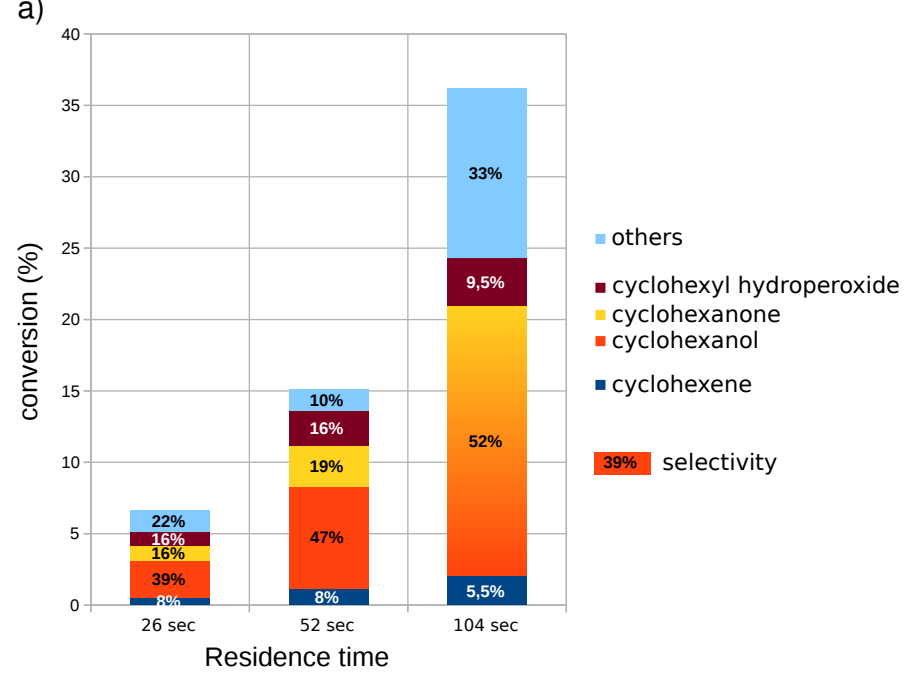

b)

\begin{tabular}{lccc}
\hline Reaction time & $26 \mathrm{~s}$ & $52 \mathrm{~s}$ & $104 \mathrm{~s}$ \\
\hline Gas flow rate $\left(\mathrm{ml} \cdot \mathrm{min}^{-1}\right)$ & 2 & 1.5 & 0.5 \\
Cyclohexane flow rate $\left(\mu \mathrm{l} \cdot \mathrm{min}^{-1}\right)$ & 24 & 12 & 6 \\
Selectivity in oxygenated products & $71 \%$ & $82 \%$ & $62 \%$ \\
Total conversion & $7 \%$ & $15 \%$ & $36 \%$ \\
Percentage of $\mathrm{O}_{2}$ used & $7 \%$ & $11 \%$ & $31 \%$ \\
\hline
\end{tabular}

Fig. 9 a) Distribution of the reaction product of cyclohexane in a $\mathrm{O}_{2}$ plasma for various residence times of the liquid phase in the plasma. The remaining to $100 \%$ is cyclohexane. The number inside the bars stand for the selectivity of each product amongst the whole of them. In the 2 min case, the two very close peaks of cyclohexanol and cyclohexanone have merged because of their very close retention times. b) Experimental parameters, measured conversion and selectivity in oxygenated products (cyclohexanol + cyclohexanone + cyclohexyl hydroperoxide), and calculation of the fraction of oxygen gas actually incorporated inside the liquid phase. plasma discharge $50|75| 77|101,103| 105$. Possible factors explaining this difference are (i) the use of a liquid cyclohexane flow providing an effective product trapping and preventing over-oxidations, (ii) the use of pure oxygen gas to form ROS whose high reactivity quenches other radical reactions (like recombination), and (iii) the low heating of the non-thermal discharge preventing undesired high temperature reactions.

The absence of polymer or, more generally, of significant overreaction, is permitted by the trapping of the reaction products by a liquid flow, as clearly stated by the teams of Locke 50 or Kudryashov 75 .

The experiments of cyclohexane oxidation led by the team of Locke ${ }^{50 \mid 77 / 101+103}$ used a water film flow, which was also the source of oxidizing species. They observed up to $7.45 \%$ conversion of hexane with selectivities of $44 \%, 27 \%$ and $25 \%$ for oxygenated products (alcohols, ketones and hydroperoxides), alkenes and fragmentation products, respectively 50 .

Reactions with water are initiated by $\mathrm{HO}^{\circ}$ and $\mathrm{H}^{\circ}$ whose reactivities lead to different reaction pathways than oxygen (reactive species $\mathrm{O}_{2}, \mathrm{O}^{*}$, and $\mathrm{HOO}^{\circ}$ ), which partially explain why the subsequent selectivity is not as good as in our experiments.

However, the main problems coming from the use of water are the following. Firstly, it dramatically decreases the energy efficiency due to a major production of hydrogen peroxide $(0.54 \mathrm{~mol} / \mathrm{kWh})$. Only a twentieth of that energy was used to oxidize cyclohexane ${ }^{77}(0.0324 \mathrm{~mol} / \mathrm{kWh}$, among which $0.0215 \mathrm{~mol} / \mathrm{kWh}$ for cyclohexanol and cyclohexanone). By comparison, our energy yield was $1.48 \mathrm{~mol} / \mathrm{kWh}$ for the whole oxygenated products.

Secondly, calculations with published data give a $0.36 \mathrm{mmol}^{-1}$ concentration of oxygenated products in the out-flowing aqueous solution. In other words, the output constitutes a large amount of water with highly diluted organic compounds which will be difficult and costly to extract and purify, especially for purposes of industrialization. By contrast, our setup performs a continuous enrichment of the liquid phase, delivering a fairly highly concentrated, readily usable, organic liquid.

Our results are similar with earlier works of cylcohexane oxidation by Kudryashov et al.75|105, who used $\mathrm{O}_{2}$ as oxidant gas. According to the provided data, the molar $\mathrm{O}_{2} /$ cyclohexane ratio of incoming reactants was 0.5 , indeed very close to our conditions, and they achieved a 3\% conversion of the cyclohexane, with a claimed nearly $100 \%$ selectivity in cyclohexanol and cyclohexanone (although they did not detail the collection method), and they obtained an energy efficiency of $0.7 \mathrm{~mol} / \mathrm{kWh}$. The trapping liquid being the condensed hydrocarbons on the walls, we speculate that a poor control of its flow made it difficult to increase its residence time inside the plasma, and to keep a good homogeneity of the plasma when increasing the power, thus limiting the conversion.

Focusing now on earlier works on cyclohexane oxidation by Kudryashov et al.75/105, they achieved a 3\% conversion of cyclohexane with a claim of nearly $100 \%$ selectivity in cyclohexanol and cyclohexanone and an energy efficiency of $0.7 \mathrm{~mol} / \mathrm{kWh}$. Their results are very similar to ours, which can be explained by 
the use of similar experimental conditions. They ondeed used $\mathrm{O}_{2}$ as oxidant gas with a molar $\mathrm{O}_{2}$ /cyclohexane ratio of 0.5 in a coaxial DBD reactor with $1 \mathrm{~mm}$ of gaseous gap and walls thermostated at $20^{\circ} \mathrm{C}$. Our better performances in terms of conversion and energy efficiency are likely due to the better control over the gas/liquid diphasic flow and the discharge homogeneity in the plasma/liquid microreactor.

\section{Conclusion and outlook}

A microfluidic device was presented comprising two innovations which open the road to true plasma chemistry and new chemical routes for synthesis of organic molecules using less solvent, no catalysts and in mild conditions (atmospheric pressure, ambient temperature). A co-current biphasic gas-liquid flow was stabilised over the metre scale thanks to triple line pinning at a sharp edge, and a homogeneous dielectric barrier discharge was triggered in the gas with a $\mathrm{kHz}$ sine high voltage excitation. This provided excited species, ions and radicals which quickly transferred into the adjacent liquid phase, or directly reacted in gas phase. The products were trapped inside the liquid phase, thus preventing over-reaction.

Contrary to numerous other reactions leading to overoxidations, early results using oxygen have been shown and confirm the possibility of activating aliphatic $\mathrm{C}-\mathrm{H}$ bonds to perform controlled partial oxidation, leading mainly to a cyclohexanol/cyclohexanone mixture ("KA oil") with $80 \%$ selectivity. This high selectivity, associated to a relatively high conversion - more than $10 \%$ - is unprecedented in the literature. We therefore claim a certain level of control on the plasma reactivity.

The ambition is now to explore new reactivities by using other gases such as $\mathrm{H}_{2}$ for (de)hydrogenation, $\mathrm{CO} / \mathrm{CO}_{2}$ for carbonylation, $\mathrm{NH}_{3}$ for amination, and mixtures with inert gases like $\mathrm{Ar}$ and $\mathrm{He}$ to modulate their reactivity.

Finally, the plasma biphasic microreactor presented here may be used to perform not only specific functionalization of molecules but also radical polymerization reactions.

This concept has the potential to rapidly integrate the sector of fine chemistry where microfluidic devices for flow chemistry are already increasingly used, since they are well-suited for hazardous or exothermic reactions.

\section{Acknowledgements}

This work has received the support of "Institut PierreGilles de Gennes" (laboratoire d'excellence, "Investissements d'avenir" program ANR-10-IDEX-0001-02 PSL and ANR-10-LABX31; équipement d'excellence, "Investissements d'avenir" program ANR-10- EQPX-34), Sorbonne Université (PhD Grant), and CNRS.

\section{Notes and references}

1 A. Fridman, A. Chirokov and A. Gutsol, Journal of Physics D: Applied Physics, 2005, 38, R1-R24.

2 U. Kogelschatz, Plasma Chemistry and Plasma Processing, 2003, 23, 1-46.

3 S. E. Babayan, J. Y. Jeong, A. Schütze, V. J. Tu, M. Moravej, G. S. Selwyn and R. F. Hicks, Plasma Sources Science and Technology, 2001, 10, 573.
4 K. R. Kull, M. L. Steen and E. R. Fisher, Journal of Membrane Science, 2005, 246, 203-215.

5 R. Morent, N. D. Geyter, T. Desmet, P. Dubruel and C. Leys, Plasma Processes and Polymers, 2011, 8, 171-190.

6 S. Guruvenket, G. M. Rao, M. Komath and A. M. Raichur, Applied Surface Science, 2004, 236, 278-284.

7 W. Von Siemens, Poggendorfs Annale, 1857, 102, 66-122.

8 U. Kogelschatz, Process Technologies for Water Treatment, Springer US, 1988, pp. 87-118.

9 H. L. Chen, H. M. Lee, S. H. Chen and M. B. Chang, Industrial \& Engineering Chemistry Research, 2008, 47, 2122-2130.

10 L. Wei, D. Yuan, Y. Zhang, Z. Hu, Z. Tan, G. Dong and S. Tao, The European Physical Journal D, 2014, 68, 17.

11 J. H. Lozano-Parada and W. B. Zimmerman, Chemical Engineering Science, 2010, 65, 4925-4930.

12 M. H. Kim, J. H. Cho, S. B. Ban, R. Y. Choi, E. J. Kwon, S.-J. Park and J. G. Eden, Journal of Physics D: Applied Physics, 2013, 46, 305201.

13 H.-H. Kim, Plasma Processes and Polymers, 2004, 1, 91-110.

14 B. M. Penetrante, R. M. Brusasco, B. T. Merritt and G. E. Vogtlin, Pure and Applied Chemistry, 2009, 71, 1829-1835.

15 K. H. Becker, Introduction to Complex Plasmas, Springer, Berlin, Heidelberg, 2010, pp. 367-394.

16 H.-H. Kim, Y. Teramoto, A. Ogata, H. Takagi and T. Nanba, Plasma Chemistry and Plasma Processing, 2015, 36, 45-72.

17 I. Matsveev, Plasma Assisted Combustion, Gasification, and Pollution Control, Outskirts Press, 2013, vol. Volume 1. Methods of Plasma Generation for PAC.

18 F. Oshima, S. Stauss, C. Ishii, D. Z. Pai and K. Terashima, Journal of Physics D: Applied Physics, 2012, 45, 402003.

19 M. V. Mishin, V. S. Protopopova and S. E. Alexandrov, Russian Journal of General Chemistry, 2015, 85, 1209-1221.

20 D. L. Sun, R. Y. Hong, F. Wang, J. Y. Liu and M. Rajesh Kumar, Chemical Engineering Journal, 2016, 283, 9-20.

21 S. Ghosh, T. Liu, M. Bilici, J. Cole, I.-M. Huang, D. Staack, D. Mariotti and R. M. Sankaran, Journal of Physics D: Applied Physics, 2015, 48, 314003.

22 S. Askari, M. Macias-Montero, T. Velusamy, P. Maguire, V. Svrcek and D. Mariotti, Journal of Physics D: Applied Physics, 2015, 48, 314002.

23 G. Saito and N. Sakaguchi, Nanotechnology, 2015, 26, 235602.

24 G. Panomsuwan, A. Watthanaphanit, T. Ishizaki and N. Saito, Physical Chemistry Chemical Physics, 2015, 17, 13794-13799.

25 J. Friedrich, Plasma Processes and Polymers, 2011, 8, 783802.

26 F. Hochart, J. Levalois-Mitjaville and R. De Jaeger, Polymer, 2000, 41, 3159-3166.

27 L. O'Toole, A. J. Beck, A. P. Ameen, F. R. Jones and R. D. Short, Journal of the Chemical Society, Faraday Transactions, 1995, 91, 3907.

28 Y.-J. Liu, X.-Z. Jiang and L. Wang, Plasma Chemistry and Plasma Processing, 2007, 27, 496-503. 
29 H. Sekiguchi, M. Ando and H. Kojima, Journal of Physics D: Applied Physics, 2005, 38, 1722.

30 D. Ascenzi, P. Franceschi, G. Guella and P. Tosi, The Journal of Physical Chemistry A, 2006, 110, 7841-7847.

31 G. R. Dey, A. Sharma, K. K. Pushpa and T. N. Das, Journal of Hazardous Materials, 2010, 178, 693-698.

32 D.-W. Lee, J.-H. Lee, B.-H. Chun and K.-Y. Lee, Plasma Chemistry and Plasma Processing, 2003, 23, 519-539.

33 A. Indarto, IEEE Transactions on Dielectrics and Electrical Insulation, 2008, 15, 1038-1043.

34 T. Nozaki and K. Okazaki, Journal of the Japan Petroleum Institute, 2011, 54, 146-158.

35 T. Nozaki and K. Okazaki, Catalysis Today, 2013, 211, 2938.

36 C. De Bie, J. van Dijk and A. Bogaerts, The Journal of Physical Chemistry C, 2015, 119, 22331-22350.

37 B. Wang and H. M. Guan, Catalysis Letters, 2016, 146, 21932199.

38 B. Eliasson, C.-j. Liu and U. Kogelschatz, Industrial \& Engineering Chemistry Research, 2000, 39, 1221-1227.

39 A. Indarto, J.-W. Cho, H. Lee, H. K. Song and J. Palgunadi, Journal of Rare Earths, 2006, 24, 513-518.

40 T. Nozaki, N. Muto, S. Kado and K. Okazaki, Catalysis Today, 2004, 89, 57-65.

41 C.-j. Liu, R. Mallinson and L. Lobban, Journal of Catalysis, 1998, 179, 326-334.

42 V. Hessel, A. Anastasopoulou, Q. Wang, G. Kolb and J. Lang, Catalysis Today, 2013, 211, 9-28.

43 N. Na, Y. Xia, Z. Zhu, X. Zhang and R. G. Cooks, Angewandte Chemie International Edition, 2009, 48, 2017-2019.

44 M. Tezuka and M. Iwasaki, Thin Solid Films, 2002, 407, 169173.

45 S. E. Boganov, S. V. Kudryashov, A. Y. Ryabov, A. I. Suslov, S. S. Rynin, M. P. Egorov and O. M. Nefedov, Plasma Chemistry and Plasma Processing, 2014, 34, 1345-1370.

46 T. Ihara, T. Ouro, T. Ochiai, M. Kiboku and Y. Iriyama, Bulletin of the Chemical Society of Japan, 1996, 69, 241-244.

47 D. Mei and X. Tu, Journal of CO2 Utilization, 2017, 19, 6878.

48 T. Nozaki, A. Hattori and K. Okazaki, Catalysis Today, 2004, 98, 607-616.

49 A. Ağıral, T. Nozaki, M. Nakase, S. Yuzawa, K. Okazaki and J. G. E. (Han) Gardeniers, Chemical Engineering Journal, 2011, 167, 560-566.

50 S. Bresch, R. Wandell, H. Wang, I. Alabugin and B. R. Locke, Plasma Chemistry and Plasma Processing, 2015, 36, 553584.

51 K. H. Schoenbach and K. Becker, The European Physical Journal $D, 2016,70,1-22$.

52 K. H. Becker, K. H. Schoenbach and J. G. Eden, Journal of Physics D: Applied Physics, 2006, 39, R55.

53 J. G. Eden, S. J. Park, J. H. Cho, M. H. Kim, T. J. Houlahan, B. Li, E. S. Kim, T. L. Kim, S. K. Lee, K. S. Kim, J. K. Yoon, S. H. Sung, P. Sun, C. M. Herring and C. J. Wagner, IEEE
Transactions on Plasma Science, 2013, 41, 661-675.

54 S. Lomel, L. Falk, J. M. Commenge, J. L. Houzelot and K. Ramdani, Chemical Engineering Research and Design, 2006, 84, 363-369.

55 L. N. Protasova, M. Bulut, D. Ormerod, A. Buekenhoudt, J. Berton and C. V. Stevens, Organic Process Research \& Development, 2013, 17, 760-791.

56 B. Gutmann, D. Cantillo and C. O. Kappe, Angewandte Chemie International Edition, 2015, 54, 6688-6728.

57 R. Srinivasan, I.-M. Hsing, P. E. Berger, K. F. Jensen, S. L. Firebaugh, M. A. Schmidt, M. P. Harold, J. J. Lerou and J. F. Ryley, AIChE Journal, 1997, 43, 3059-3069.

58 S. Mori, A. Yamamoto and M. Suzuki, Plasma Sources Science and Technology, 2006, 15, 609.

59 A. Agiral, L. Lefferts and J. G. E. Gardeniers, IEEE Transactions on Plasma Science, 2009, 37, 985-992.

60 J. C. T. Eijkel, H. Stoeri and A. Manz, Analytical Chemistry, 1999, 71, 2600-2606.

61 J. C. T. Eijkel, H. Stoeri and A. Manz, Analytical Chemistry, 2000, 72, 2547-2552.

62 T. S. Anderson, J. H. Ma, S.-J. Park and J. G. Eden, IEEE Transactions on Plasma Science, 2008, 36, 1250-1251.

63 S. H. Sung, I. C. Hwang, S.-J. Park and J. G. Eden, Applied Physics Letters, 2010, 97, 231502.

64 J. H. Cho, S.-J. Park and J. G. Eden, Applied Physics Letters, 2012, 101, 253508.

65 P. Sichler, S. Büttgenbach, L. Baars-Hibbe, C. Schrader and K.-H. Gericke, Chemical Engineering Journal, 2004, 101, 465-468.

66 C. Trionfetti, A. Ağıral, L. Lefferts and K. Seshan, The Journal of Physical Chemistry C, 2008, 112, 4267-4274.

67 A. Ağıral, C. Trionfetti, L. Lefferts, K. Seshan and J. G. E. H. Gardeniers, Chemical Engineering \& Technology, 2008, 31, 1116-1123.

68 S.-K. Fan, Y.-T. Shen, L.-P. Tsai, C.-C. Hsu, F.-H. Ko and Y.-T. Cheng, Lab on a Chip, 2012, 12, 3694-3699.

69 Y. Yamanishi, S. Sameshima, H. Kuriki, S. Sakuma and F. Arai, 2013 Transducers Eurosensors XXVII: The 17th International Conference on Solid-State Sensors, Actuators and Microsystems (TRANSDUCERS EUROSENSORS XXVII), 2013, pp. 1795-1798.

70 T. Seto, S.-B. Kwon, M. Hirasawa and A. Yabe, Japanese Journal of Applied Physics, 2005, 44, 5206.

71 D. R. Reyes, M. M. Ghanem, G. M. Whitesides and A. Manz, Lab on a Chip, 2002, 2, 113-116.

72 J. Lim, D. R. Reyes and A. Manz, Lab on a Chip, 2003, 3, 137-140.

73 Y. Wang, J. H. Ni, S. Zhong, X. Zhang, Z. Liang, C. Liu, S.-J. Park and J. G. Eden, Journal of Physics D: Applied Physics, 2016, 49, 415206.

74 H. Suhr, Pure and Applied Chemistry, 1974, 39, 395-414.

75 S. V. Kudryashov, G. S. Shchegoleva, E. E. Sirotkina and A. Y. Ryabov, High Energy Chemistry, 2000, 34, 112-115.

76 S. V. Kudryashov, A. Y. Ryabov, G. S. Shchegoleva, V. Y. 
Savinykh and A. I. Suslov, High Energy Chemistry, 2011, 42, 51-55.

77 R. Wandell, S. Bresch, K. Hsieh, I. Alabugin and B. Locke, IEEE Transactions on Plasma Science, 2014, 42, 1195-1205.

78 M. A. Malik, Plasma Chemistry and Plasma Processing, 2009, 30, 21-31.

79 T. Yano, I. Uchiyama, F. Fukawa, K. Teranishi and N. Shimomura, IEEE International Power Modulators and High Voltage Conference, Proceedings of the 2008, 2008, pp. 80-83.

80 Y. Matsui, N. Takeuchi, K. Sasaki, R. Hayashi and K. Yasuoka, Plasma Sources Science and Technology, 2011, 20, 034015.

81 M. Zhang, PhD thesis, Paris 6, 2016.

82 M. Zhang, S. Ognier, N. Touati, L. Binet, C. Thomas, P. Tabeling and M. Tatoulian, Green Processing and Synthesis, 2017, 6, 63-72.

83 M. Tatoulian, S. Ognier and M. Zhang, 2017.

84 J. F. Oliver, C. Huh and S. G. Mason, Journal of Colloid and Interface Science, 1977, 59, 568-581.

85 V. Liimatainen, V. Sariola and Q. Zhou, Advanced Materials, 2013, 25, 2275-2278.

86 L. Hu, M. Wu, W. Chen, H. Xie and X. Fu, Experimental Thermal and Fluid Science, 2017, 87, 50-59.

87 J. Wengler, S. Ognier, S. Al Ayoubi and M. Tatoulian.

88 U. Schuchardt, D. Cardoso, R. Sercheli, R. Pereira, R. S. daCruz, M. C. Guerreiro, D. Mandelli, E. V. Spinacé and E. L. Pires, Applied Catalysis A: General, 2001, 211, 1-17.

89 A. K. Suresh, M. M. Sharma and T. Sridhar, Industrial \& Engineering Chemistry Research, 2000, 39, 3958-3997.

90 A. Bhattacharya and A. Mungikar, The Canadian Journal of Chemical Engineering, 2008, 81, 220-229.
91 J.-R. Chen and S.-K. Chen, Journal of Loss Prevention in the Process Industries, 2005, 18, 97-106.

92 D. Bartolo, G. Degré, P. Nghe and V. Studer, Lab on a Chip, 2008, 8, 274-279.

93 J. P. Borra, N. Jidenko, J. Hou and A. Weber, Journal of Aerosol Science, 2015, 79, 109-125.

94 T. C. Manley, Transactions of The Electrochemical Society, 1943, 84, 83-96.

95 Z. Falkenstein and J. J. Coogan, Journal of Physics D: Applied Physics, 1997, 30, 817.

96 I. Biganzoli, R. Barni, A. Gurioli, R. Pertile and C. Riccardi, Journal of Physics: Conference Series, 2014, 550, 012039.

97 A. Aota, K. Mawatari, S. Takahashi, T. Matsumoto, K. Kanda, R. Anraku, A. Hibara, M. Tokeshi and T. Kitamori, Microchimica Acta, 2009, 164, 249.

98 Y. Mori, T. Vandeven and S. Mason, Colloids and Surfaces, 1982, 4, 1-15.

99 H. Kusumaatmaja, C. M. Pooley, S. Girardo, D. Pisignano and J. M. Yeomans, Physical Review E, 2008, 77, 067301.

100 A. Aota, K. Mawatari and T. Kitamori, Lab on a Chip, 2009, 9, 2470-2476.

101 R. J. Wandell and B. R. Locke, IEEE Transactions on Plasma Science, 2014, 42, 2634-2635.

102 K. C. Hsieh, H. Wang and B. R. Locke, Plasma Processes and Polymers, 2016, n/a-n/a.

103 K. Hsieh, H. Wang and B. R. Locke, Journal of Hazardous Materials, 2016, 317, 188-197.

104 W. A. Dietz, Journal of Chromatographic Science, 1967, 5, 68-71.

105 S. V. Kudryashov, G. S. Shchegoleva, A. Y. Ryabov and E. E. Sirotkina, High Energy Chemistry, 2002, 36, 349-354. 